\title{
reviews
}

To review one volume of Needham's great monument-in-the-making is like trying to make an architectural assessment of a single pillar of a temple. But one is encouraged in the attempt because a pillar is not a bad analogy. The superstructure of modern science is sustained on many singular supports; Greek atomism, mediaeval astronomy, Renaissance navigation, and so on. One of the pillars, alchemy, changes its appearance as one changes one's viewpoint.

There has been a lot of change in the historical assessment of alchemy. For a time it was viewed as the main forerunner of modern scientific chemistry; then as mere superstition and charlatanism; then as a lesser light to technological chemistry. Now we are beginning to re-assess it yet again as something respectable in its own right, a body of practice and belief that should be viewed not in terms of modern science and modern society, but as something of its own time. It is one of the outstanding merits of Needham's work that at the same time as he makes us look for the first time at a culture we did not pretend to know, he also makes us look afresh at the western science we thought we did know. This is true in general of his whole enterprise, but particularly clear in this volume.

It is at once chastening and stimulating to see Chinese alchemy studied with an eye to chemical detail which has not been applied so closely by any writer about western alchemy in the present generation of historians of western science.

Alchemy was concerned with many things, but the big thing was the distinctive character of gold. Gold was astonishing stuff to the ancient world. Familiarity with it never bred contempt, because one characteristic marked it off from all else; it was incorruptible. It survived all trials and could be recovered pure and undiminished from alloys and disguises by the process of cupellation. True: it was beautiful, but other things were beautiful. The imitation of its beauty was one thing: aurifiction, the production of the appearance of gold. But could gold be made: was true aurifaction a possibility? And if one form of matter could be incorruptible, could not Man be made incorruptible? So far, so simplc. These are the familiar themes of western alchemy. The value

\section{Science ancient and modern}

\section{Frank Greenaway}

Science and Civilisation in China. Vol. 5: Chemistry and Chemical Technology. Part 2: Spagyrical Discovery and Invention: Magisteries of Gold and Immortality. By Joseph Needham with $\mathrm{Lu}$ Gwei-Djen. Pp. xxxii+510. (Cambridge University Press: London, October 1974.) £12.00; $\$ 35.00$.

of Needham's work lies in his expounding Chinese alchemy as a thing distinct in itself, having its own moral values, social relations and methods of enquiry. If some resemblances, some identities, are discovered which show Chinese and western alchemy to have a common basis and to have arrived at some common conclusions, this is for a good reason: "While we can easily see that artistic styles and expressions, religious ceremonies and doctrines, or different kinds of music, have tended to be incommensurable; for mathematics, science and technology the case is altered-man has always lived in an environment essentially constant in its properties, and his knowledge of it, if true, must therefor tend towards a constant structure".

Is the limited career of Chinese alchemy to be considered in Spenglerian terms, an aspect of a quasi-organic cultural growth and decay, or in Kuhnian terms, an aspect of the adoption of a compelling fashion of thought in a line of succession without progress? Needham respectfully rejects the Spenglerian pessimism but will not accept a naive Kuhnism. In fact, he will not accept entire any of the currently packaged philosophies of history, but insists that he is engaged in an enquiry which will lead to a new appreciation of the origins, development and internal and external relations of Chinese science when the work is done. His study of Chinese science leads him to remind us how provisional is our modern scientific 'knowledge'.

"It is neither independent of the accidents of Western European history, nor is it a final court of appeal for the eschatological judgment of the value of past scientific discoveries either in West or East. It is a reliable measuring stick so long as we never forget its transitory nature."

One of the most difficult exercises for the historian of science is to relate the techniques of a historical period to modern scientific and technical knowledge. Needham's treatment of the metallurgical practices which the alchemists used for precious and base metals is exemplary. These pages can be recommended to any reader, whether he cares about Chinese alchemy or not, who wants a brief, logical (and so far as I can gauge, pretty complete) survey of all early metallurgical developments. There are some surprises, such as the widespread use of cupronickel, the as yet unexplained occurrence of some specimens of aluminium, and the extent of the trade in zinc.

When Needham has to deal with the derivative human theme of alchemy, the elixir of life, the drug of deathlessness, he does so by relating it most skilfully to the technical, metallurgical theme. He shows how the idea of physical immortality emcrged almost imperceptibly out of the idea of longevity. There is, however, no one persistent view to be shown. There were many religions in China, influential successively or simultaneously, and each had its own philosophy of the nature of human life and its prolongation. In each, alchemical ideas could play a part. The descriptions of religious observance, incense burning in particular, are very well done, the accounts of unfamiliar liturgical and ritual customs never being obscured by the inevitably complex detail.

The excellence of the scholarly apparatus of these successive volumes is well known and needs no further praise. Nor does Needham's unfailing courtesy and generosity to his collaborators, whether they contributed to a whole chapter or a single line.

The value of this volume, only one of the four projected for the whole of Chinese chemistry, is likely to be as much in its stimulus to the reappraisal of western alchemy as in its original raison-d'être. A successful and convincing history of scientific chemistry as a whole has yet to be written. It would be strange, yet somehow satisfactory, if the stimulus to a new approach to a critique of modern chemical science should come from this splendid study of things "far away and long ago". 